\title{
Duration of load revisited
}

\section{Hoffmeyer, Preben; Sørensen, John Dalsgaard}

\section{Published in:}

Wood Science and Technology

Link to article, DOI:

10.1007/s00226-007-0154-5

Publication date:

2007

\section{Document Version}

Publisher's PDF, also known as Version of record

Link back to DTU Orbit

\section{Citation (APA):}

Hoffmeyer, P., \& Sørensen, J. D. (2007). Duration of load revisited. Wood Science and Technology, 41(8), 687711. https://doi.org/10.1007/s00226-007-0154-5

\section{General rights}

Copyright and moral rights for the publications made accessible in the public portal are retained by the authors and/or other copyright owners and it is a condition of accessing publications that users recognise and abide by the legal requirements associated with these rights.

- Users may download and print one copy of any publication from the public portal for the purpose of private study or research.

- You may not further distribute the material or use it for any profit-making activity or commercial gain

- You may freely distribute the URL identifying the publication in the public portal

If you believe that this document breaches copyright please contact us providing details, and we will remove access to the work immediately and investigate your claim. 


\title{
Duration of load revisited
}

\author{
Preben Hoffmeyer · John Dalsgaard Sørensen
}

\begin{abstract}
A duration of load study representing 13 years of testing was recently terminated. Preliminary results have been published over the years. This paper represents the final account of the study, which was focused on the influence of moisture content on time to failure for structural timber subjected to bending under constant load conditions. Two constant moisture conditions $(\mathrm{MC}=11$ and 20\%) and one condition of varying moisture (MC between 11 and 20\%) were applied. A total of 816 Norway spruce boards of dimensions $44 \times 95 \times 1,800 \mathrm{~mm}^{3}$ were included. Eight groups of non-destructively matched samples were formed. Four groups were subjected to short-term strength tests, and four groups were subjected to long-term tests. Creep and time to failure were monitored. Time to failure as a function of stress level was established and the reliability of stress level assessment was discussed. A significant mechanosorptive effect was demonstrated both in terms of increased creep and shortening of time to failure. The test results were employed for the calibration of four existing duration of load models. The effect of long-term loading was expressed as the stress level $\mathrm{SL}_{50}$ to cause failure after 50 years of loading. $\mathrm{SL}_{50}$ was found to be of the order 0.60 for $\mathrm{MC}=11 \%, 0.50$ for $\mathrm{MC}=20 \%$ and 0.44 for MC varying between 11 and $20 \%$. The test results revealed no evidence of a threshold stress level. A reliability based calibration of load-duration factors was performed using probabilistic models of loads and of the short-term and longterm strengths. For permanent and imposed library loads, reliability-based
\end{abstract}

\footnotetext{
P. Hoffmeyer ( ()

Department of Civil Engineering, Technical University of Denmark,

Building 118, 2800 Kgs Lyngby, Denmark

e-mail: ph@byg.dtu.dk

J. D. Sørensen

Department of Civil Engineering, Aalborg University,

Sohngaardsholmsvej 57, 9000 Aalborg, Denmark

e-mail: jds@civil.aau.dk
} 
estimation of the load duration factor gave almost the same results as direct, deterministic calibration.

\section{Introduction}

Wood and wood products experience a significant loss of strength and stiffness when loaded over a period of time. For more than 30 years this phenomenon of creep-rupture, often referred to as the duration of load (DOL) effect, has been subject to particular interest for everyone in the timber engineering research community concerned with safe and efficient engineering design. For a comprehensive review of important DOL research results, reference is made to Hoffmeyer (2003).

The present paper reports a recently terminated DOL study, which lasted for more than 13 years. While preliminary results were reported over the years, this paper represents the final account of results. The experimental study was focused on the influence of moisture content on time to failure for structural timber subjected to bending under constant load conditions. Two constant moisture conditions and one condition of varying moisture were applied.

The discussion and implementation of results fall into three parts. The first part is concerned with the reliability connected with the assessment of short-term strength. For interpretation of results from DOL experiments to be reliable, the assessment of the actual stress level of individual specimens must be reliable. Since a specimen cannot be broken twice, the short-term strength must be assessed without breaking the specimen. The paper presents three methods of predicting short-term strength and discusses the reliability of predictions. In the second part, four existing DOL models are introduced and calibrated to fit the experimental data. In the third part, reliability based calibration of load duration factors $k_{\bmod }$ is performed using probabilistic models of loads as well as short-term and long-term strength.

\section{Materials}

A brief account of the material used is given below. For a full description, reference is made to Hoffmeyer (1990). The material was Swedish grown Norway spruce (Picea abies). Preliminary dimensions were $50 \times 100 \mathrm{~mm}^{2}, 3.6 \mathrm{~m}$ long. Specimens were planed to $44 \times 95 \mathrm{~mm}^{2}$ and cut to a length of $1.8 \mathrm{~m}$ with the qualitydetermining defect at centre.

The material was selected from a sample of about 9,000 boards. The quality corresponded to an average appearance grade V ("quinta"), which is the next lower of six appearance grades. First, a random sample of about 300 boards was selected to establish a preliminary relationship between bending strength and various nondestructive parameters including machine grading (Cook-Bolinder). Subsequently, limits were imposed on the marginal knot area ratio $(0.27 \leq \mathrm{MKAR} \leq 1)$ and MOE from machine grading $(6.5 \mathrm{GPa} \leq \mathrm{MOE} \leq 11.4 \mathrm{GPa})$. This left about 1,100 specimens. Most of the 7,900 rejected specimens had predicted strength 
values above those of the selected boards. The final sample, therefore, represents a quality at the very low end of the original sample. The final sample was divided into sub-samples of 51 specimens each, using the non-destructive parameters to ensure an equal distribution of bending strength in all sub-samples.

Four sub-samples were conditioned at $55 \% \mathrm{RH}$ and four at $90 \% \mathrm{RH}$ to establish short-term strength values for moisture content levels at about 11 and 20\%, respectively. Two sub-samples were used in each of four groups comprising longterm tests at different moisture conditions. Thus, in total, 16 sub-samples or 816 boards were included.

\section{Methods}

A brief account of the methods used is given below. For a full description, reference is made to Hoffmeyer (1990). All tests were carried out as four-point bending tests with a span of $1,720 \mathrm{~mm}$ and a mid-section of $600 \mathrm{~mm}$. For all specimens of the final sample, the modulus of elasticity $\left(E_{11}\right)$ in dry condition was assessed as the average of measurements at both wide faces of the midsection. In addition, a short-span $(200 \mathrm{~mm})$ measurement $\left(E_{11}\right.$, short $)$ was taken at the tension edge at the location of the weakest cross-section. The weakest crosssection was at the centre, and the edge supposed to be weakest was subjected to tension. Loading of specimens for short-term tests was displacement controlled and adjusted in such a manner that ultimate load was reached within $(500 \pm 120)$ seconds. The same displacement rate was used for uploading the long-term loaded specimens. The displacement rate corresponded to an average loading rate of about $500 \mathrm{MPa} / \mathrm{h}$.

\section{Short-term mechanical test}

Four sub-samples were conditioned at 55\% RH and four at $90 \% \mathrm{RH}$ to establish short-term strength values at low and high moisture content, resulting in a total of 408 boards tested. As part of a research cooperation, the short-term testing of boards at low RH was carried out by Princes Risborough Laboratory, UK (Fewell 1986), and the results were subsequently made available to the present study. For these four sub-samples, at low moisture content, less information on board characteristics is available.

\section{Long-term mechanical tests}

Eight sub-samples were used for long-term tests. Two sub-samples were used to form each of the following groups:

- Group 1: Long-term load at 55\% RH. Load equal to the 5\% quantile of shortterm strength distribution at 55\% RH (28.2 MPa). 
- Group 2: Long-term load at $90 \%$ RH. Load equal to the 5\% quantile of shortterm strength distribution at $90 \% \mathrm{RH}(26.5 \mathrm{MPa})$.

- Group 3: Long-term load at $90 \%$ RH. Load equal to the $15 \%$ quantile of shortterm strength distribution at $90 \% \mathrm{RH}(31.4 \mathrm{MPa})$.

- Group 4: Long-term load at RH varying between 55 and 90\%. Load equal to the $5 \%$ quantile of short-term strength distribution at 90\% RH (26.5 MPa).

Test rigs were constructed to simultaneously accommodate 200 long-term bending tests. The long-term load was applied to the specimen through a load lever pulled towards a pulley by the weight of a steel barrel (Fig. 1). The pulley ratio of 5.16 means that the long-term load of the order 6-7 $\mathrm{kN}$ is accomplished by a steel barrel weight of the order $120-140 \mathrm{~kg}$.

Long-term load was applied at the same rate as used for the short-term tests. The short-term strength of boards failing during application of load was registered. Long-term deflection at the centre was measured as was long-term deformations of the central $200 \mathrm{~mm}$ edges in both compression and tension. Tests at constant climate were accomplished in climate rooms $( \pm 0.5 \% \mathrm{RH})$. As an extra precaution, all boards were sealed in $0.2 \mathrm{~mm}$ polyethylene tubing. Boards subjected to cyclically varying relative humidity were loaded in the moist condition while still sealed in polyethylene tubing. After 1 week of creep measurements, the tubing was removed and the varying humidity was accomplished by varying the climate of the whole room. The boards were first given 3 weeks of dry climate, then 4 weeks of moist climate, 4 weeks of dry climate, etc. The change of relative humidity from one steady state to another took place in approximately $6 \mathrm{~h}$. Boards surviving a long-term load of about 13 years were allowed to rest for 2 months before taken to failure in a short-term test.

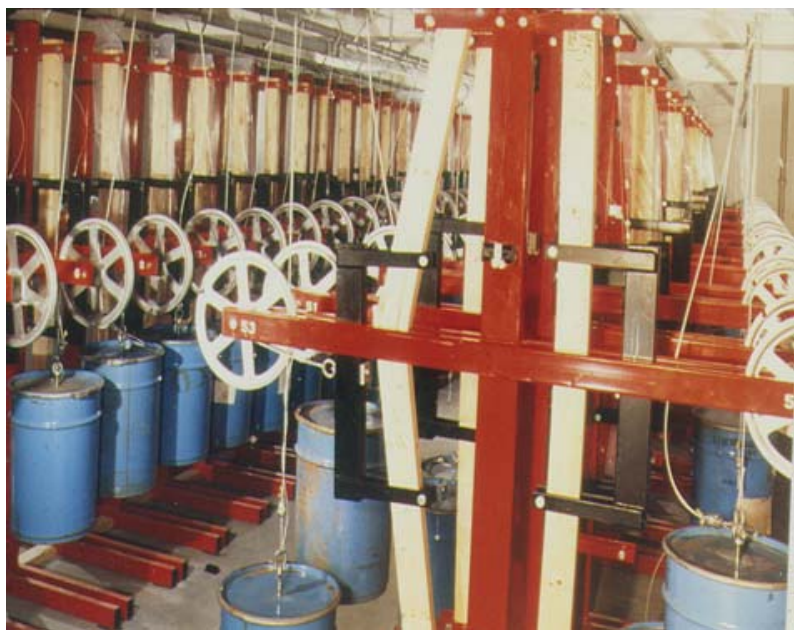

Fig. 1 Long-term test rigs to accommodate two boards each 


\section{Duration of load models}

In order for the experimental data to be useful in predicting DOL behaviour under conditions (e.g. load level, moisture content) different from those of the present experiments, an appropriate model must be made available. Four models are considered: the models by Gerhards (1979) and Foschi and Yao (1986) are empirical expressions in which damage is seen as a state variable, $\alpha$, ranging from zero at the outset to one at failure. The model by Nielsen (1979) and the linear elastic fracture mechanics (LEFM) model used in Sørensen and Svensson (2005) are based on theory of fracture mechanics of viscoelastic materials.

Gerhards' model

Damage accumulation model:

$$
\frac{\mathrm{d} \alpha}{\mathrm{d} t}=\exp \left(-a+b \frac{\sigma}{f_{0}}\right)
$$

Solution:

$$
\mathrm{SL}=\left(A-B \log t_{\mathrm{f}}\right) \varepsilon
$$

where

SL long-term strength/short-term strength (measured by test), i.e. SL $=\sigma / f_{0}$

$t_{\mathrm{f}} \quad$ time to failure $(\mathrm{h})$

$A, B$ regression coefficients

$\varepsilon \quad$ estimation error; modeled as LogNormally distributed with expected value and standard deviation $\sigma_{\varepsilon}$

Foschi and Yao's model

Damage accumulation model:

$$
\begin{aligned}
& \frac{\mathrm{d} \alpha}{\mathrm{d} t}=A\left(\frac{\sigma}{f_{0}}-\eta\right)^{B}+C\left(\frac{\sigma}{f_{0}}-\eta\right)^{D} \alpha ; \quad \frac{\sigma}{f_{0}}>\eta \\
& \frac{\mathrm{d} \alpha}{\mathrm{d} t}=0 ; \quad \frac{\sigma}{f_{0}} \leq \eta
\end{aligned}
$$

Solution: time to failure

$$
t_{\mathrm{f}}=\left(\frac{\sigma}{k}+\frac{1}{C\left(\frac{\sigma}{k}-\eta\right)^{D}} \ln \left(\frac{1+\lambda}{\alpha_{0}+\lambda}\right)\right) \varepsilon
$$

where: 


$$
\alpha_{0}=\left(\frac{\frac{\sigma}{f_{0}}-\eta}{1-\eta}\right)^{B+1} ; \quad \lambda=\frac{k(B+1)}{C f_{0}(1-\eta)^{D}}\left(\frac{\sigma}{f_{0}}-\eta\right)^{B-D}
$$

$B, C, D$ regression coefficients

$k \quad$ ramp load rate $=500 \mathrm{MPa} / \mathrm{h}$

$\eta \quad$ lower threshold $=0.5$

$\varepsilon \quad$ estimation error; modeled as LogNormally distributed with expected value and standard deviation $\sigma_{\varepsilon}$

Nielsen's model

The model described in Nielsen (1979) is based on fracture mechanics and can be written as

$$
\frac{\mathrm{d} \alpha}{\mathrm{d} t}=\frac{(\pi \mathrm{FL})^{2}}{8 q \tau} \alpha\left(\frac{\sigma}{f_{0}}\right)^{2}\left(\left(\alpha\left(\frac{\sigma}{f_{0}}\right)^{2}\right)^{-1}-1\right)^{-\frac{1}{b}}
$$

Solution: time to failure

$$
t_{\mathrm{f}}=\left(\frac{8 q \tau}{(\pi \times \mathrm{FL} \times \mathrm{SL})^{2}} \int_{1}^{\mathrm{SL}^{-2}} \frac{(\varphi-1)^{1 / b}}{\varphi} \mathrm{d} \varphi\right) \varepsilon
$$

where

$b$ regression coefficient

FL regression coefficient $=0.25$

$\tau$ regression coefficient

$q=\left[\frac{1}{2(b+1)(b+2)}\right]^{1 / b}$

$\varepsilon \quad$ estimation error; modeled as LogNormally distributed with expected value and standard deviation $\sigma_{\varepsilon}$

\section{LEFM model}

Like the Nielsen model, the LEFM model is based on fracture mechanics. The LEFM model used is a two-parameter model omitting a third "variable-moistureparameter" included in Sørensen and Svensson (2005). The stress level corresponding to failure is obtained from: 


$$
\mathrm{SL}=\frac{A}{\sqrt{1+\left(\frac{t_{\mathrm{f}}}{\tau}\right)^{b}}} \varepsilon
$$

where
$b, A, \tau \quad$ regression coefficients
$\varepsilon \quad$ estimation error; modeled as LogNormally distributed with expected value and standard deviation $\sigma_{\varepsilon}$

\section{Experimental data and discussion}

Experimental duration of load studies including structural timber is very costly. In order to secure optimal utilization, the present study's most essential data on time to failure are available to other researchers interested in model calibration and $k_{\text {mod }}$ calculation. The data are available as electronic supplementary material at http://www.byg.dtu.dk/upload/institutter/byg/trae/esm.pdf. The detailed account of materials and methods may be downloaded from the web address defined with Hoffmeyer (1990).

\section{Matching of sub-samples}

Matched strength distributions are a basic precondition for success of the present DOL study. The quality of matching may be assessed, e.g. by comparing features of the short-term sub-samples tested. Such a comparison shows an almost perfect match of the distributions of MOE and marginal knot area (Hoffmeyer 1990). The short-term strength values, which were the targets of the matching process, also show a remarkable agreement (Table 1).

Table 1 Short-term strength of four sub-samples at low moisture condition and four sub-samples at high moisture conditions

\begin{tabular}{llllll}
\hline Sub-sample no. & MC $(\%)$ & \multicolumn{3}{l}{ Bending strength, $f_{\mathrm{R}}(\mathrm{MPa})$} \\
\cline { 3 - 6 } & & Mean & Min. & Max. & COV (\%) \\
\hline 1 & 20 & 36.1 & 22.7 & 47.2 & 15.5 \\
2 & 20 & 36.5 & 22.4 & 49.2 & 16.4 \\
3 & 20 & 36.7 & 22.0 & 48.2 & 15.7 \\
4 & 20 & 36.6 & 24.1 & 50.0 & 14.6 \\
5 & 11 & 38.4 & 23.5 & 51.5 & 16.2 \\
6 & 11 & 38.5 & 24.4 & 53.4 & 16.1 \\
7 & 11 & 38.7 & 25.2 & 54.5 & 16.1 \\
8 & 11 & 38.9 & 25.5 & 54.9 & 16.2 \\
\hline
\end{tabular}


The quality of matching may also be assessed from the number of specimens that broke on uploading (BOL). About 306 boards and 102 boards were loaded to the 5th and 15th-percentile of short-term strength. This calls for 31 specimens to break before full load is reached. The same number of BOL-boards was seen in the actual tests. Further evidence of good matching is presented below.

Estimation of stress level

Results from duration of load tests are most often shown in a plot of stress level, SL, versus logarithm of time to failure. The stress level is defined as SL $=f / f_{0}$ where $f$ is the actual long-term strength and $f_{0}$ is the (unknown) failure stress in a short-term ramp load test. Two methods are employed to predict stress level of individual specimens. One method is using the equal rank assumption (Madsen 1971) to predict short-term strength $f_{0}$. The corresponding stress level is termed SLR. The other method is using non-destructive parameters to predict short-term strength. The corresponding stress level is termed SLP.

\section{Equal rank assumption method}

Strength values from short-term tests are ranked in ascending order, and boards subjected to long-term loading are ranked in order of ascending time to failure. Subsequently, short-term strength values corresponding to an equal rank are assigned to the boards subjected to long-term loading, and the stress level SLR is calculated. Data from group 1 (dry) are shown in Fig. 2 together with the corresponding short-term results. Fourteen of these boards survived 13 years of loading and were subsequently subjected to short-term tests to failure. Only one of the 14 boards showed a possible short-term strength reduction of the order of $10 \%$. This leads to the important conclusion that the equal rank assumption does work, since 13 of the 14 surviving beams are matched by the 13 strongest beams from the short-term strength distribution. It also allows the conclusion that, at low moisture content, damage is not necessarily accumulated over a long period of time, but may rather develop over a relatively short period to failure. However, this may not be the case at high moisture content: two beams survived 13 years of loading at constant high moisture content. The results of the subsequent short-term tests indicated a strength loss of the order of $30 \%$ (Fig. 2). Thus, the behaviour at high moisture content seems to be different from that at low moisture content. This may suggest that, at a high moisture content, damage accumulates over longer periods of time than at a low moisture content.

\section{Non-destructive parameters method}

The other method employed to predict short-term strength, $f_{0}$, utilizes selected nondestructive parameters to estimate the short-term strength of the specimens under long-term loading. The following multiple regression equation based on four subsamples (204 boards) proved to be the best predictor of short-term strength, $f_{\mathrm{P}, 20}$, at about $20 \%$ moisture content. 
Fig. 2 Hundred and two boards loaded to the fifth-percentile $(+)$. Also included are the short-term reference strength data (diamonds). a Fourteen boards of group 1 $(\mathrm{MC}=11 \%)$ survived 13 years of loading and were subsequently subjected to short-term testing. b Two boards of group $2(\mathrm{MC}=20 \%)$ survived 13 years of loading and were subsequently subjected to short-term testing
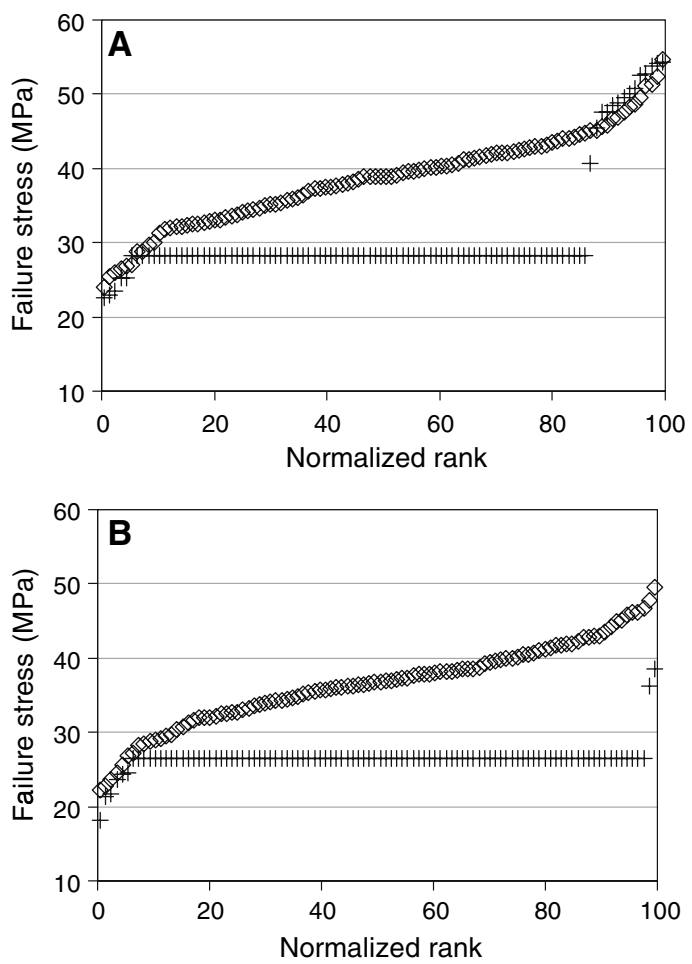

$f_{\mathrm{P}, 20}=-49.53+0.001332 E_{11}-0.1667 \mathrm{MKAR}+0.02941 \rho_{20}+7.136 \ln \left(E_{11, \text { short }}\right)$

where

MKAR marginal knot area ratio

$\rho_{20}$ density of the board at about $20 \%$ moisture content.

The marginal knot area ratio proved a disappointing predictor of bending strength $\left(R^{2}=0.16\right)$. A more refined assessment of the influence of knots using the technique of Foley (2003) was attempted, but no significant improvement was obtained.

A relation for short-term strength similar to (9) cannot be produced at $11 \%$ moisture content, since non-destructive parameters for the four sub-samples subjected to short-term tests at low moisture content are not available. Instead, short-term strength, $f_{\mathrm{P}, 11}$, of the specimens subjected to long-term loads in dry condition is estimated by using (9) subsequently corrected for the influence of moisture. The latter is done by utilizing a relation established from the eight sub-samples of boards subjected to short-term tests at two different moisture levels (10):

$$
f_{\mathrm{P}, 11}=8.896+0.4976 f_{\mathrm{P}, 20}+0.008488 f_{\mathrm{P}, 20}^{2}
$$


In order to relate the duration of load results presented later to the $k_{\text {mod }}$ factors of Eurocode 5 (2004) it is necessary to introduce short-term strength values $f_{\mathrm{P}, 12}$ and $f_{\mathrm{R}, 12}$ corresponding to the reference climate conditions $20^{\circ} \mathrm{C}$ and $65 \% \mathrm{RH}$ or approximately $12 \%$ moisture content. This is done by assuming a linear relationship between strength and wood moisture content in the range of 55-90\% RH. Shortterm strength values at $12 \%$ moisture content are then produced by employing (10) together with a sorption isotherm for the spruce timber.

The quality of fit of predicted strength, $f_{\mathrm{P}, 12}$, to test results, $f_{\mathrm{R}, 12}$, is assessed by the Maximum Likelihood Method. The following linear model is used

$$
f_{\mathrm{P}, 12}\left(f_{\mathrm{R}, 12}\right)=\left(a+b f_{\mathrm{R}, 12}\right) X_{M}
$$

where

$a, b \quad$ regression parameters

$X_{M}$ estimation error; modeled as LogNormally distributed with expected value $\mu_{X}=1$ and standard deviation $\sigma_{M}$

The fit to data is shown in Table 2 and Fig. 3. The coefficient of variation (COV) of the linear model quantified by $\sigma_{M}$ is $7.9 \%$ which indicates a relative high uncertainty. The Maximum Likelihood Method also gives estimates of the statistical uncertainties as shown in Table 2 . The results show that especially the slope $b$ has a high statistical uncertainty.

Classical linear regression gives a coefficient of determination equal to $R^{2}=0.64$ which also indicates a relatively low correlation between predicted and measured strengths. With no constant term (fit through origo): $R^{2}=0.45$. A quadratic model with fit through origo produces $R^{2}=0.64$.

Time to failure based on the equal rank assumption

Figure 4 shows stress level $S L R$ as a function of the logarithm of time to failure for the four groups tested. Stress level, is based on ranked short-term strength values corresponding to the actual moisture content during the test. For group 4 (varying climate), the moisture content of specimens subjected to short-term tests is $20 \%$. A linear version of the so-called Madison curve (Wood 1951) is included:

$$
\mathrm{SL}=90.4-6.3 \log t_{\mathrm{f}}
$$

Table 2 Fit of predicted short-term strength $f_{\mathrm{P}, 12}$ to test results $f_{\mathrm{R}, 12}$ by the Maximum Likelihood Method

\begin{tabular}{lcll}
\hline & $a$ & $b$ & $\sigma_{M}$ \\
\hline Best estimate & 13.0 & 0.657 & 0.079 \\
Coefficient of variation $(\%)$ & 4.9 & 9.2 & 5.0 \\
\hline
\end{tabular}

Correlation: $\rho(a ; b)=-0.99 ; \rho\left(a ; \sigma_{X}\right)=-0.01 ; \rho\left(b ; \sigma_{X}\right)=0.02$ 
Fig. 3 Least squares fit of predicted bending strength, $f_{\mathrm{P}, 12}$, as a function of test result, $f_{\mathrm{R}, 12}$

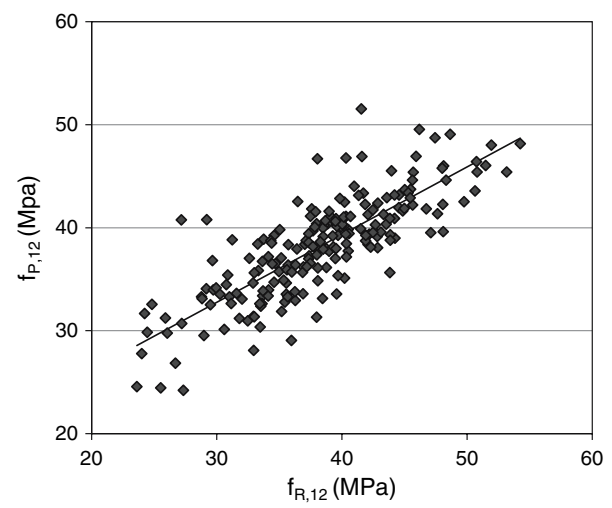

The curve is based on results from small clear bending specimens tested in dry condition, and frequently used as a reference. In comparison, the present test results show a less severe DOL behaviour for dry structural timber and a more severe DOL behaviour for moist structural timber.

Figure 5 shows a segment of Fig. 4 for times to failure longer than $1 \mathrm{~h}$ and stress level adjusted to short-term strength at reference conditions $\left(20^{\circ} \mathrm{C}\right.$ and $\left.65 \% \mathrm{RH}\right)$. As would be expected, the adjustment to reference conditions results in a significant reduction of stress levels for the structural timber at $20 \%$ moisture content.

The data of Fig. 5 are used for both DOL-model calibrations and for calibration of the load duration factor $k_{\text {mod }}$. The cut-off at $1 \mathrm{~h}$ is introduced so that model predictions of long-term behaviour are not inappropriately influenced by results from specimens loaded only for a very short time. A linear regression of SLR on

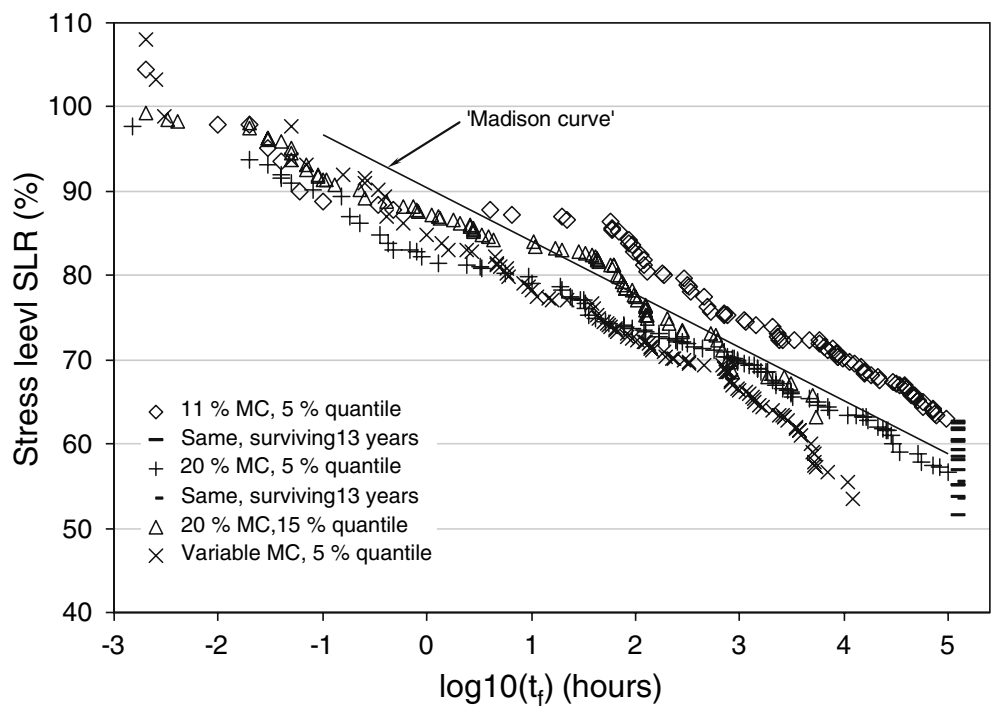

Fig. 4 DOL-curves for four groups of 102 boards each tested under different moisture conditions. Stress level based on short-term strength at actual moisture content $(M C)$. Madison curve included as a reference 


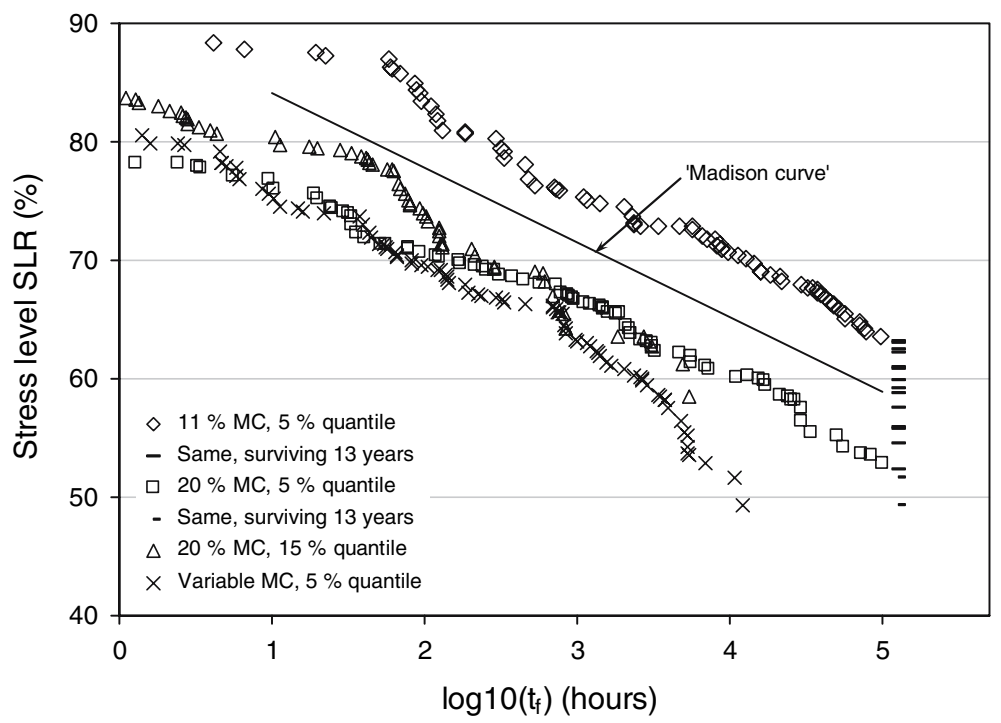

Fig. 5 Segment of Fig. 4 for times to failure longer than $1 \mathrm{~h}$ and stress level SLR based on short-term strength at reference conditions $\left(20^{\circ} \mathrm{C}\right.$ and $\left.65 \% \mathrm{RH}\right)$. Madison curve included as a reference

$\log _{10}\left(t_{\mathrm{f}}\right)$ predicts the stress level at 50 years to be SLR $=0.60$ for MC $=11 \%$, $\mathrm{SLR}=0.50$ for $\mathrm{MC}=20 \%$ and $\mathrm{SLR}=0.44$ for varying MC. Thus, varying the moisture content between 11 and $20 \%$ clearly results in a mechanosorptive effect causing shorter times to failure than those obtained for tests at any of the constant moisture levels. Failures were also observed to occur particularly frequent during the first part of a sorption period. The last board at varying moisture failed after 1.4 years, at a time when there were 17 boards remaining at constant high moisture.

Time to failure based on sample median values

To avoid the uncertainties involved in using the equal rank assumption, the time to failure assessment may be based on "sample median values" (e.g. Hoffmeyer 1990; Hanhijärvi et al. 1998; Gustafsson et al. 1998). This procedure takes a complete sample to produce one data point. The stress level is taken as the actual long-term stress for a particular sample over the sample median of short-term strength. The time to failure is expressed as the sample median of $\log _{10}\left(t_{\mathrm{f}}\right)$.

The present study allows a treatment of five samples subjected to five different load levels. Two of the samples are groups 2 and 3 (high moisture content) and group 1 (low moisture content) of the present study. Two additional samples are taken from a collaborate study (Fewell 1986). The latter samples are identical with those of the present study. They were conditioned at the low moisture content and loaded to the 15 and $30 \%$ quantiles of the short-term strength distributions.

For the three samples of the present study, sample median values are expressed as " $50 \%$ values" calculated as the average values of boards nos. 51 and 52 (sample 
size $=102)$. Short-term strengths of the samples were taken at reference condition $\left(20^{\circ} \mathrm{C}, 65 \% \mathrm{RH}\right)$.

For the two samples of the collaborate study, the stress level is taken as the actual long-term stress for the two samples (31.97 and $35.24 \mathrm{MPa}$ ) over the sample median of short-term strength as was used for group 1 above. The resulting stress levels are $\mathrm{SL}=83.3$ and $91.8 \%$. No detailed time to failure data was available for these two samples. Therefore, the two sample median values of $\log _{10}\left(t_{\mathrm{f}}\right)$ had to be extracted from the graphical data representation of DOL curves in Fewell (1986) corresponding to the two stress levels calculated above. The values of $\log _{10}\left(t_{\mathrm{f}}\right)(\mathrm{h})$ were 1.82 and 0.88 , respectively. Results are shown in Fig. 6. Fewell (1986) presents a graph somewhat related to Fig. 6. However, it should be noted that in Fewell's analysis, boards that broke on loading (BOL) were omitted. This would not make sense for the present purpose of assessing the sample median values.

A linear regression of sample median values predicts the stress level at 50 years to be $\mathrm{SL}=0.57$ for $\mathrm{MC}=11 \%$ and $\mathrm{SL}=0.48$ for $\mathrm{MC}=20 \%$, which is not much different from the values predicted from the equal rank assumption method (Table 6). This coincidence suggests (Hoffmeyer 2003) no significant effect of timber quality on DOL behaviour for the range of timber qualities used. A similar conclusion was made by Fewell (1986) by comparing DOL results from samples of the collaborate study to his DOL results from samples of higher quality.

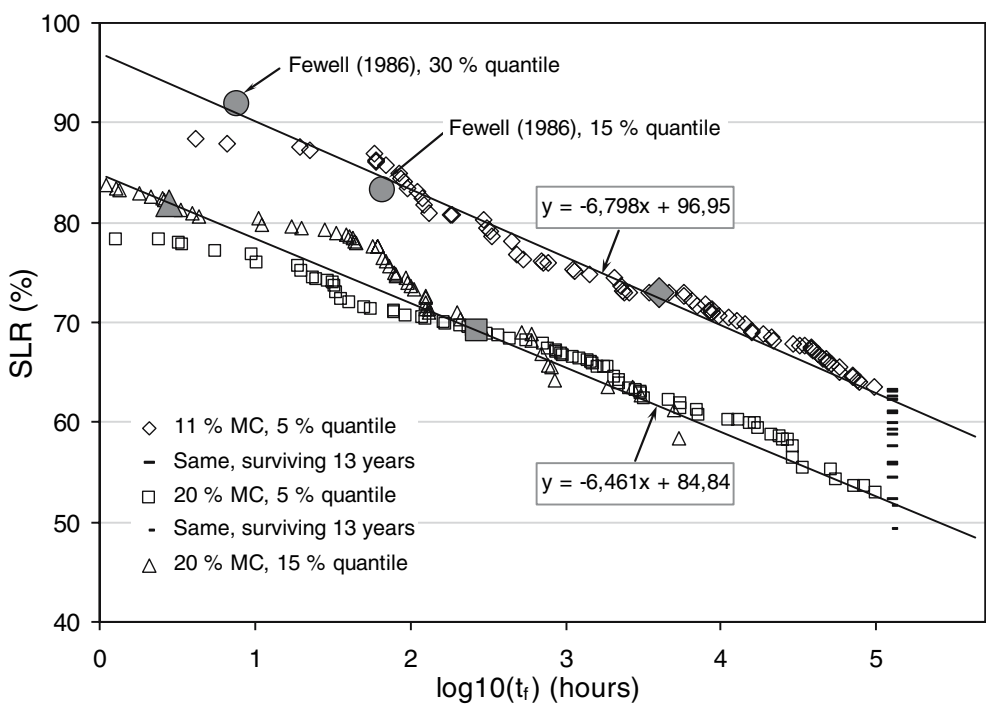

Fig. 6 DOL-curves for the samples at constant moisture conditions (groups 1-3). Large, filled data labels are sample median values. Two additional sample median values are included from a collaborative study (Fewell 1986). Trendlines for median values at the two moisture levels are included 
Time to failure based on non-destructive assessment of short-term strength

As an alternative to the use of the equal rank method, the predicted stress level (SLP) of a particular board may be assessed by expressing the ratio of actual applied stress over the short-term strength as expressed by Eqs. (2) and (3). The results are treated in a subsequent paragraph on calibration of models. Results are seen in Table 6 and Fig. 8.

\section{Creep}

The creep component $\psi(t)$ of the total deformation is expressed as the ratio between the time dependent deformation and the initial elastic deformation. Creep data are fitted to the power function $\psi(t)=(T / \tau)^{b}$, where $T$ is the time and $b$ and $\tau$ are regression parameters. The latter parameter is termed the doubling time because $\tau$ defines the time when total deformation is twice the initial deformation. Table 3 gives creep parameters as average values for specimens of each group. The data shown are based on global deflection. More detailed information also including data based on creep strain in tension and compression is available in (Hoffmeyer 1990).

The doubling time $\tau$ for group 3 (load: 15\% quantile) is shorter than for group 2 (load: $5 \%$ quantile) which indicates non-linear creep. The very short doubling time for group 4 (load: $5 \%$ quantile) compared to that of group 2 reflects the significant influence of mechanosorption. Part of such behaviour is attributed to the gradual formation of the microstructural damage known as "slip planes"; such damage is facilitated by moisture changes (Hoffmeyer 1989; 1993).

Nielsen's model and the LEFM model contain regression parameters rooted in the assumption that the time dependent decrease of the modulus of elasticity (creep factor) may also be expressed by the power function $(T / \tau)^{b}$. It is conceivable that such creep at the microstructural level is reflected in creep behaviour at a macrostructural level and thus transformed into a material property available to experimental verification. An attempt was therefore made to apply the experimental data (Table 3) from the creep tests to the calibration of the two models. The results were discouraging, as may also be concluded by comparing the experimental values of $b$ and $\tau$ from Table 3 with the $b$ and $\tau$ parameters of Tables 4 and 5. The experimental data show $b$ to increase and $\tau$ to decrease from group 1 through group 4 , i.e. for increasingly severe moisture or load conditions. This overall pattern is not found to be consistent in either of the two models, and particularly the $\tau$ values of the models are way off compared to the doubling times found from tests. Thus, the $b$

Table 3 Average creep parameters based on global deflection

\begin{tabular}{lrl}
\hline & \multicolumn{1}{c}{$\tau(\mathrm{h})$} & \multicolumn{1}{c}{$b$} \\
\hline Group 1 & $19 \times 10^{6}$ & 0.23 \\
Group 2 & 7,200 & 0.27 \\
Group 3 & 2,600 & 0.31 \\
Group 4 & 800 & 0.35 \\
\hline
\end{tabular}


and $\tau$ parameters of the models are to remain regression coefficients that are not applicable as materials properties assessed from bending creep tests.

\section{Calibration of models}

Short-term strength assessed by equal rank assumption

Calibration of regression parameters is performed for all four models using the Maximum Likelihood Method. Table 4 shows the best estimates. Including the surviving specimens of groups 1 and 2 proved to enhance the estimates, and survivors are therefore included in the estimation of regression parameters. Models utilizing the best fit parameters of Table 4 are shown in Fig. 7. The parameters of the four duration of load models are fitted using the Maximum Likelihood Method including the number of surviving specimens in the statistical analysis.

The results shown in Fig. 7 and Table 4 show that all four damage accumulation models can be calibrated to fit the data very well. For Gerhards' model and the LEFM model, where the model uncertainty quantified by $\sigma_{\varepsilon}$ is related to the stress level (SL), there are no significant differences in model uncertainties. For the Foschi $\&$ Yao model and the Nielsen model, the model uncertainty is related to the time to failure, $t_{\mathrm{f}}$, and it is seen that in general, the Foschi \& Yao model has the smallest model uncertainty.

Table 4 shows the $b$ parameter of Nielsen's model to be scattered around an average value of 0.20 . A calibration with a fixed regression coefficient $b=0.20$ and with $\tau$ as the only variable regression coefficient resulted in only marginally larger model uncertainty. For this "one-parameter-model" the $\tau$ values for groups 1-4 were $1,060,19.1,30.3$ and $7.2(\mathrm{~h})$, respectively.

Short-term strength assessed from non-destructive parameters

In order to model the long-term stress level based on non-destructive indicators and include the uncertainty related to estimation of the short-term strength, the following model is used:

$$
\mathrm{SL}=\frac{f}{f_{\mathrm{R}}}=\frac{f}{f_{\mathrm{P}}} \frac{f_{\mathrm{P}}}{f_{\mathrm{R}}}=\operatorname{SLP}\left(f_{\mathrm{P}}\right) \frac{f_{\mathrm{P}}\left(f_{\mathrm{R}}\right)}{f_{\mathrm{R}}}
$$

where

\begin{tabular}{|c|c|}
\hline$f$ & long-term strength \\
\hline$f_{\mathrm{P}}$ & predicted short-term strength \\
\hline$f_{\mathrm{R}}$ & measured (real) short-term strength \\
\hline $\operatorname{SLP}\left(f_{\mathrm{P}}, \varepsilon\right)=\frac{f}{f_{\mathrm{P}}}$ & $\begin{array}{l}\text { stress level fitted to damage model using non-destructive } \\
\text { parameters }\end{array}$ \\
\hline$\left(f_{\mathrm{R}}, X_{M}\right)$ & $\begin{array}{l}\text { predicted short-term strength as a function of real short-term } \\
\text { strength by (11) }\end{array}$ \\
\hline
\end{tabular}




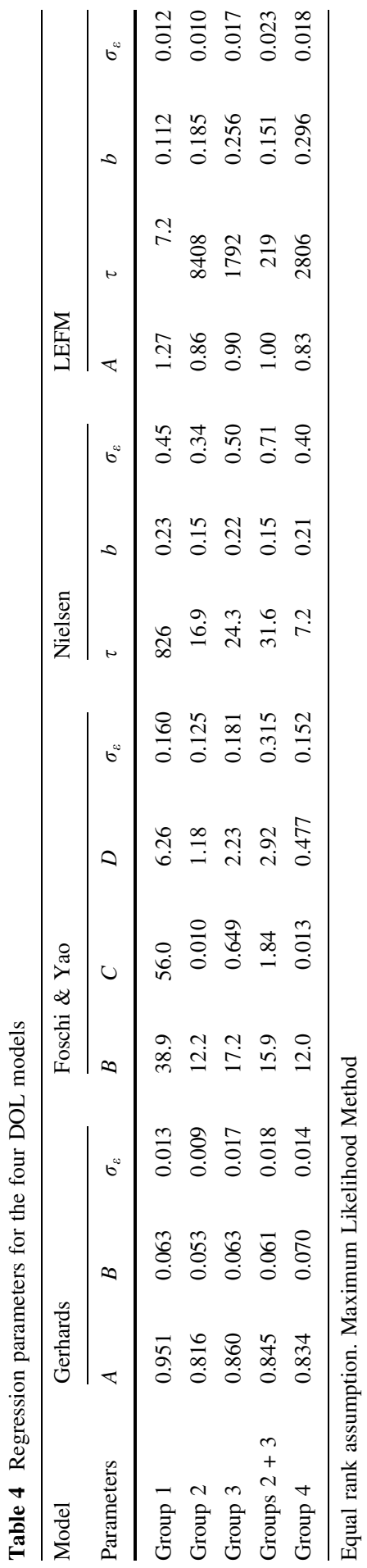


Fig. 7 Test results based on equal rank assumption. Best fits of the four models are shown
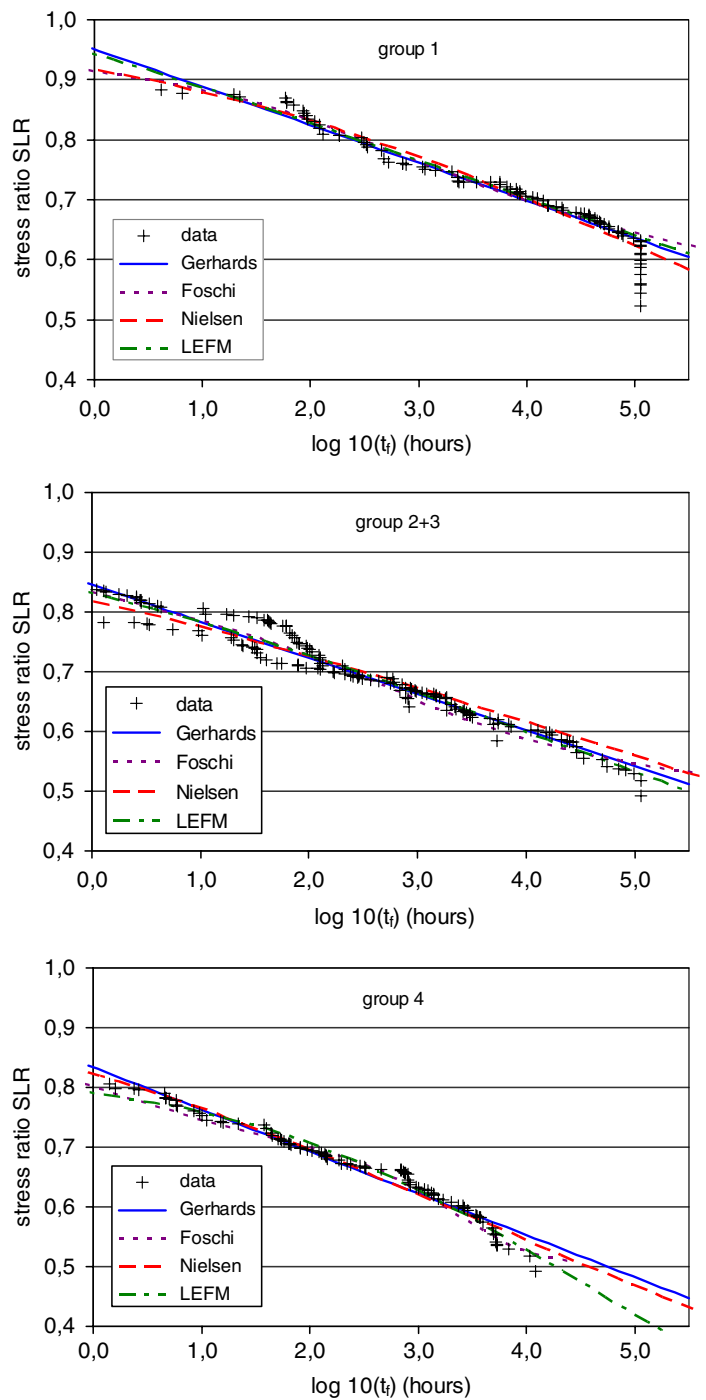

$\varepsilon$ $X_{M}$ estimation error related to fit of long-term strength as function of predicted short-term strength (with standard deviation $\sigma_{\varepsilon}$ ), see (1)-(8)

estimation error related to fit of predicted short-term strength as a function of real short-term strength (with standard deviation $\sigma_{M}$ ), see (11)

The long-term strength is fitted using short-term strengths predicted by nondestructive indicators and the four damage accumulation models. The best estimates of the parameters obtained by the Maximum Likelihood Method are shown in Table 5 and the data fits are presented in Fig. 8. The results show that all four 
Table 5 Regression parameters for the four DOL models

\begin{tabular}{|c|c|c|c|c|c|c|c|c|c|c|c|c|c|c|}
\hline \multirow{2}{*}{$\begin{array}{l}\text { Model } \\
\text { Parameters }\end{array}$} & \multicolumn{3}{|c|}{ Gerhards } & \multicolumn{4}{|c|}{ Foschi \& Yao } & \multicolumn{3}{|c|}{ Nielsen } & \multicolumn{4}{|c|}{ LEFM } \\
\hline & $A$ & $B$ & $\sigma_{\varepsilon}$ & $B$ & $C$ & $D$ & $\sigma_{\varepsilon}$ & $\tau$ & $b$ & $\sigma_{\varepsilon}$ & $A$ & $\tau$ & $b$ & $\sigma_{\varepsilon}$ \\
\hline Group 1 & 0.92 & 0.059 & 0.07 & 44 & 51 & 4.9 & 1.3 & 400 & 0.20 & 3.0 & 0.86 & 24,000 & 0.40 & 0.07 \\
\hline Groups 2 & 0.75 & 0.026 & 0.07 & 15 & 0.04 & 1.0 & 1.2 & 27 & 0.15 & 3.1 & 0.73 & 172,000 & 0.25 & 0.10 \\
\hline Groups 3 & 0.90 & 0.060 & 0.18 & 18 & 0.70 & 2.0 & 1.4 & 71 & 0.25 & 2.9 & 0.82 & 173,000 & 0.25 & 0.09 \\
\hline Groups $2+3$ & 0.82 & 0.039 & 0.08 & 30 & 1.2 & 3.0 & 1.2 & 55 & 0.20 & 3.1 & 0.88 & 37,000 & 0.14 & 0.10 \\
\hline Group 4 & 0.85 & 0.070 & 0.06 & 24 & 1.1 & 2.2 & 0.83 & 12 & 0.23 & 2.1 & 0.80 & 19,500 & 0.24 & 0.08 \\
\hline
\end{tabular}

Non-destructive parameters method. Maximum Likelihood Method

damage accumulation models can be calibrated to fit the data reasonably well, but with significantly larger model uncertainties than when using the equal rank assumption. This is due to the large scatter of the data points.

The above conclusion concerning the performance of Nielsen's model with a fixed value of $b=0.20$ also holds in this case. The resultant $\tau$ values for groups $1-4$ were 549, 121, 98 and $13(\mathrm{~h})$, respectively.

Stress level SL at failure after 50 years of load duration

The combined effects of duration of load and moisture are evaluated in terms of the stress level $\mathrm{SL}_{50}$ to cause failure after 50 years of permanent load. Table 6 shows $\mathrm{SL}_{50}$ values predicted by the four models with regression parameters from Tables 4 and 5. Also included are the predictions based on simple linear regression and sample median values. In general, the $\mathrm{SL}_{50}$ values predicted by the equal rank assumption agree well with the linear regression and sample average predictions. However, it is noted that the fracture mechanics based models (Nielsen and LEFM) in some cases (groups 3 and 4) result in lower SL 50 values. The predictions obtained using the non-destructive parameters are very scattered as could be expected from the uncertain estimates of the model parameters as seen in Table 5 and Fig. 8.

A lower threshold value $\eta=0.45$ in the Foschi \& Yao model was investigated, but the estimated parameters and the $\mathrm{SL}_{50}$ value were only slightly different from those obtained by using $\eta=0.5$.

As mentioned above, 13 years of test data are used. The results offer an opportunity to investigate whether a shorter time span could have produced equally reliable results. Using the equal rank assumption, Gerhards' model and group 1 data, a sensitivity study of results shows that 6-7 years of data are sufficient to obtain the same estimates of the model parameters and $\mathrm{SL}_{50}$ value with two digits of accuracy, i.e. the time span of the tests could be shortened significantly. It should be noted that this is only possible if the surviving test specimens are included in the statistical analysis using, e.g. the Maximum Likelihood Method. 
Fig. 8 Test results based on non-destructive parameters method. Best fits of Gerhards' and Nielsen's models are shown
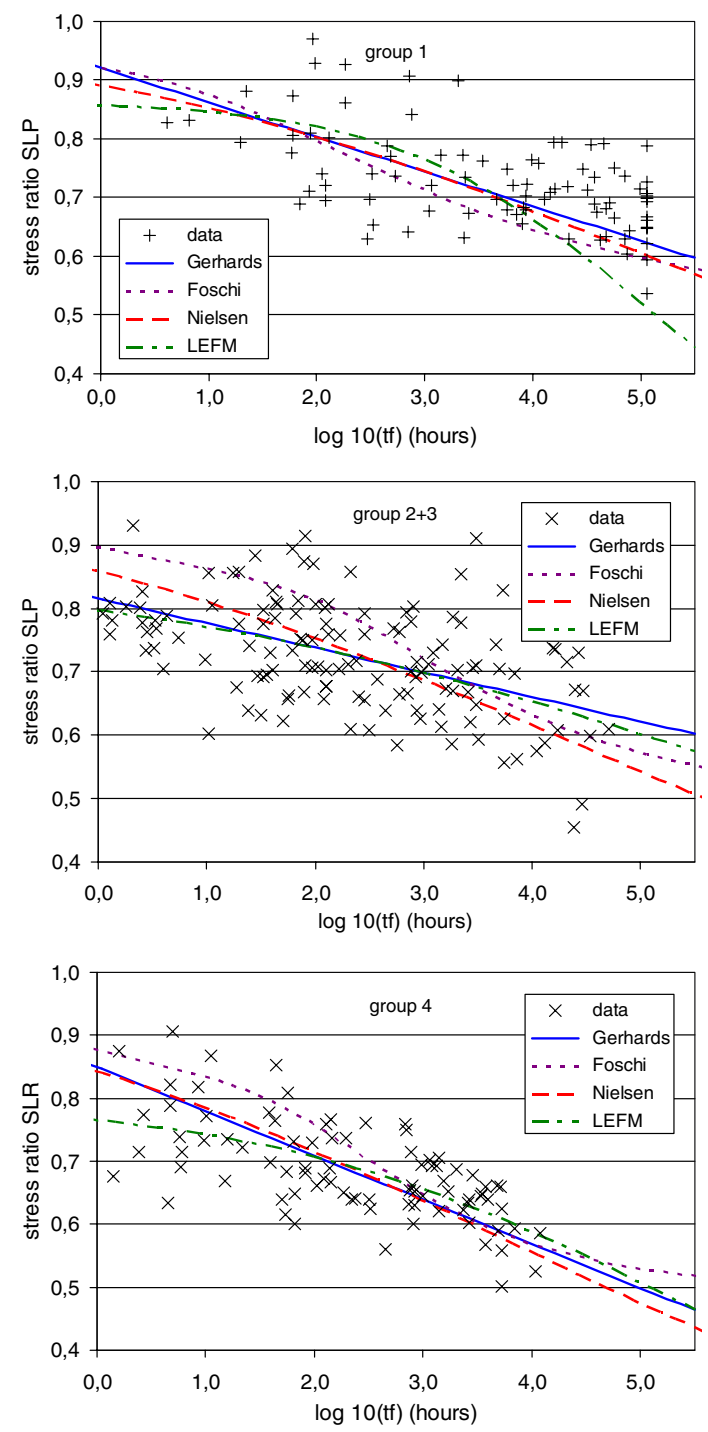

\section{Duration of load factors}

This paragraph demonstrates how reliability based calibration of load duration factors $k_{\text {mod }}$ is performed using probabilistic models of loads and short-term and long-term strength. Duration of load factors are calibrated as described in Sørensen et al. (2005).

\section{Load models}

Permanent load is modeled as normally distributed with the coefficient of variation equal to $10 \%$. 
Table 6 Average stress level SL at failure after 50 years of load duration predicted by models, simple linear regression and sample average values

\begin{tabular}{|c|c|c|c|c|c|c|c|c|c|c|}
\hline \multirow[b]{2}{*}{ Model } & \multicolumn{4}{|c|}{ Equal rank assumption } & \multicolumn{4}{|c|}{ Non-destructive parameters } & \multirow{2}{*}{$\begin{array}{l}\text { Linear } \\
\text { regr. }\end{array}$} & \multirow{2}{*}{$\begin{array}{l}\text { Sample } \\
\text { median }\end{array}$} \\
\hline & Gerhards & Foschi & Nielsen & LEFM & Gerhards & Foschi & Nielsen & LEFM & & \\
\hline Group 1 & 0.60 & 0.62 & 0.57 & 0.60 & 0.59 & 0.58 & 0.56 & 0.42 & 0.60 & 0.57 \\
\hline Group 2 & 0.52 & 0.52 & 0.51 & 0.49 & 0.60 & 0.46 & 0.52 & 0.56 & 0.52 & - \\
\hline Group 3 & 0.50 & 0.52 & 0.45 & 0.40 & 0.56 & 0.52 & 0.47 & 0.63 & 0.50 & - \\
\hline Groups $2+3$ & 0.50 & 0.53 & 0.52 & 0.49 & 0.60 & 0.55 & 0.50 & 0.57 & 0.50 & 0.48 \\
\hline Group 4 & 0.44 & 0.46 & 0.42 & 0.35 & 0.45 & 0.52 & 0.43 & 0.45 & 0.44 & - \\
\hline
\end{tabular}

Imposed (live) load is modeled in accordance with the JCSS load model (JCSS 2006) and CIB W81 (1989). As an example, imposed load in libraries is considered. The load model for this type of load is based on sustained loads which cover ordinary imposed load such as furniture, average utilization by persons, etc.

The following assumptions are made:

- the sustained load changes at the times $X_{1}, X_{2}, \ldots$ are modeled by a Poisson process. The time interval between changes is exponentially distributed with expected value $\lambda_{\text {sus }}$.

- the magnitude of the sustained load $P_{\text {sus }}$ is assumed to be Gamma distributed with expected value $\lambda_{\text {sus }}$ and standard deviation $\sigma_{\text {sus }}=\sqrt{\sigma_{v}^{2}+\sigma_{u, \text { sus }}^{2} \kappa A_{0} / A}$ with parameters defined in Table 7.

\section{Calibration of load duration factor}

Reliability based calibration of load duration factors is performed using probabilistic models of loads and short-term and long-term strength. It is assumed that the short-term strength $f_{0}$ of timber is Lognormally distributed with coefficient of variation equal to $15 \%$, and that the characteristic strength is the $5 \%$ quantile.

The following short-term limit state equation is used:

$$
g=z f_{0}-Q
$$

where $z$ is a design parameter, $f_{0}$ is the short-term strength and $Q$ is the load.

The corresponding design equation is:

Table 7 Parameters for imposed (live) load, see JCSS (2001)

\begin{tabular}{llllll}
\hline \multicolumn{5}{l}{ Sustained load } & \\
\cline { 2 - 5 } & $A_{0}\left(\mathrm{~m}^{2}\right)$ & $\mu_{\text {sus }}\left(\mathrm{kN} / \mathrm{m}^{2}\right)$ & $\sigma_{v}\left(\mathrm{kN} / \mathrm{m}^{2}\right)$ & $\sigma_{u, \text { sus }}\left(\mathrm{kN} / \mathrm{m}^{2}\right)$ & $\lambda_{\text {sus }}($ year $)$ \\
\hline Library & 2 & 1.7 & 0.5 & 1.0 & 10 \\
\hline
\end{tabular}

$A=5 \mathrm{~m}^{2}$ and $\kappa=1.778$ 


$$
\frac{z f_{0, \mathrm{C}}}{\gamma_{\mathrm{m}}}-\gamma_{Q} Q_{\mathrm{C}}=0
$$

where the characteristic values and partial safety factors in the Danish codes DS409 (2006) and DS413 (2006) are:

$f_{0, \mathrm{C}}$ characteristic value for short-term strength (5\% quantile)

$Q_{\mathrm{C}}$ characteristic value (98\% quantile in annual maximum distribution for variable loads and mean values for permanent loads)

$\gamma_{\mathrm{m}} \quad$ partial safety factor for material parameter $(=1.35)$

$\gamma_{Q}$ partial safety factor for variable load $(=1.5)$

The design variable $z$ is determined from (15) and next, the reliability index $\beta$ is calculated on the basis of (14) and the stochastic model using a so-called timeinvariant reliability problem formulation, see also Sørensen and Hoffmeyer (2000, 2001).

The following time-invariant long-term limit state equation is used for the damage accumulation models by Gerhards, Foschi \& Yao and LEFM:

$$
g=1-\alpha\left(f_{0}, X_{M}, Q, A, B, C, \varepsilon, \operatorname{SL}(z), \eta, T_{L}\right)
$$

where

$\alpha \quad$ damage function. Gives the accumulated damage after $T_{L}=50$ years with a time varying variable load $Q=Q(t)$

$T_{L} \quad$ design life ( $=50$ years)

$A, B, C, \varepsilon$ parameters in damage accumulation model

SL $\quad$ stress level $=\frac{Q}{z f_{0}}$

$\eta \quad$ threshold value

The following time-variant long-term limit state equation is used for the damage accumulation model by Nielsen:

$$
g=\operatorname{SL}(z, t)^{-2}-\alpha\left(f_{0}, X_{M}, Q, A, B, C, \varepsilon, \operatorname{SL}(z, t), \eta, T_{L}\right)
$$

The time to the first failure is obtained corresponding to the first time, when $\alpha(t)$ $\geq \operatorname{SL}(z, t)^{-2}$, i.e. a so-called time-variant reliability problem.

The design equation corresponding to the limit state function (15) is:

$$
\frac{z f_{0, \mathrm{C}}}{\gamma_{\mathrm{m}}} k_{\mathrm{mod}}-\gamma_{Q} Q_{\mathrm{c}}=0
$$

where $k_{\text {mod }}$ is the load duration factor.

The $k_{\text {mod }}$ factor is calibrated by the following steps:

1. Calculate the short-term reliability index $\beta_{50}^{\mathrm{S}}$ for a 50 year reference period using the limit state function (14) and the design equation (15). $\beta_{50}^{\mathrm{S}}$ is calculated as function of $\lambda_{\mathrm{m}}$ by simulation ( $\lambda_{Q}$ is fixed). 
2. Calculate the long-term reliability index $\beta_{50}^{\mathrm{L}}$ for a 50 year reference period using the limit state function (17) and the design equation (18) and $k_{\bmod }=1 . \beta_{50}^{\mathrm{L}}$ is calculated as a function of $\gamma_{\mathrm{m}}$ by simulation $\left(\lambda_{Q}\right.$ is fixed).

3. $k_{\text {mod }}$ is estimated from

$$
k_{\mathrm{mod}}=\frac{\gamma_{\mathrm{m}}^{\mathrm{S}}(\beta)}{\gamma_{\mathrm{m}}^{\mathrm{L}}(\beta)}
$$

for a reasonable range of values of the reliability index $\beta$ corresponding to the 50 year reference period. $\gamma_{\mathrm{m}}^{\mathrm{S}}(\beta)$ is the short-term partial safety factor as a function of $\beta$ and $\gamma_{\mathrm{m}}^{\mathrm{L}}(\beta)$ is the long-term partial safety factor as a function of $\beta$.

Results of $k_{\text {mod }}$ calibration

Tables 8 and 9 show load duration factors, $k_{\text {mod }}$ for a lifetime equal to 50 years. Two damage accumulation models are selected: Gerhards and Nielsen. They represent an empirical model and a model based on fracture mechanics. Both shortterm strength predictions based on the equal rank assumption and the nondestructive assessment are used. Further, results are shown with and without statistical uncertainties related to estimation of the short-term strength based on nondestructive parameters included in the reliability assessment (upper and lower values in tables). For comparison, also the deterministic, direct estimation of the $\mathrm{SL}_{50}$ results obtained from Table 6 is included.

The results in Table 8 for imposed library loads show that the direct and the reliability-based estimation of the load duration factor give almost the same results.

Table 8 Load duration factors $k_{\text {mod }}$

\begin{tabular}{|c|c|c|c|c|c|c|c|c|}
\hline & \multicolumn{4}{|c|}{ Gerhards } & \multicolumn{4}{|c|}{ Nielsen } \\
\hline & \multicolumn{2}{|c|}{ Eq. rank } & \multicolumn{2}{|c|}{ Non-destr. } & \multicolumn{2}{|c|}{ Eq. rank } & \multicolumn{2}{|c|}{ Non-destr. } \\
\hline & Direct & Calibr. & Direct & Calibr. & Direct & Calibr. & Direct & Calibr. \\
\hline \multirow[t]{2}{*}{ Group 1} & 0.60 & 0.60 & 0.59 & 0.59 & 0.57 & 0.58 & 0.56 & 0.57 \\
\hline & & & & 0.56 & & & & 0.54 \\
\hline \multirow[t]{2}{*}{ Group 2} & 0.52 & 0.52 & 0.60 & 0.61 & 0.51 & 0.52 & 0.52 & 0.53 \\
\hline & & & & 0.57 & & & & 0.50 \\
\hline \multirow[t]{2}{*}{ Group 3} & 0.50 & 0.51 & 0.56 & 0.72 & 0.45 & 0.47 & 0.47 & 0.53 \\
\hline & & & & 0.67 & & & & 0.50 \\
\hline \multirow[t]{2}{*}{ Group $2+3$} & 0.50 & 0.50 & 0.60 & 0.60 & 0.53 & 0.49 & 0.50 & 0.51 \\
\hline & & & & 0.57 & & & & 0.48 \\
\hline \multirow[t]{2}{*}{ Group 4} & 0.44 & 0.44 & 0.45 & 0.45 & 0.42 & 0.45 & 0.43 & 0.45 \\
\hline & & & & 0.43 & & & & 0.42 \\
\hline
\end{tabular}

Permanent loads 
Table 9 Load duration factors $k_{\text {mod }}$

\begin{tabular}{|c|c|c|c|c|}
\hline & \multicolumn{2}{|l|}{ Gerhards } & \multicolumn{2}{|l|}{ Nielsen } \\
\hline & Eq. rank & Non-destr. & Eq. rank & Non-destr. \\
\hline \multirow[t]{2}{*}{ Group 1} & 0.66 & 0.64 & 0.65 & 0.63 \\
\hline & & 0.64 & & 0.63 \\
\hline \multirow[t]{2}{*}{ Group 2} & 0.56 & 0.63 & 0.57 & 0.59 \\
\hline & & 0.63 & & 0.59 \\
\hline \multirow[t]{2}{*}{ Group 3} & 0.56 & 0.73 & 0.53 & 0.59 \\
\hline & & 0.74 & & 0.58 \\
\hline \multirow[t]{2}{*}{ Group $2+3$} & 0.56 & 0.64 & 0.58 & 0.57 \\
\hline & & 0.64 & & 0.57 \\
\hline \multirow[t]{2}{*}{ Group 4} & 0.50 & 0.52 & 0.50 & 0.50 \\
\hline & & 0.52 & & 0.50 \\
\hline
\end{tabular}

Imposed loads (library)

It is noted that if the uncertainty related to the non-destructive estimation of the short-term strength is included, then slightly smaller load duration factors are obtained. It is noted that the equal rank assumption and the non-destructive estimation of short-term strengths give almost the same load-duration factors.

The results in Table 9 for permanent load also show good agreement between equal rank and the non-destructive estimation based results for Nielsen's model, whereas for Gerhards' model, some differences are obtained.

For both permanent load and imposed library load calculations similar to those presented above have shown, that the effect on $k_{\bmod }$ is marginal if statistical uncertainty on the parameters of the damage accumulation models are included.

\section{Conclusion}

- The equal rank assumption is a reliable method for the assessment of the shortterm strength of boards subjected to long-term loading.

- Damage in dry timber seems to accumulate over a short period of time to failure. Thus, loading dry timber for a long period of time does not normally change the short-term strength. Conversely, at high moisture content indications are that damage accumulates over longer periods of time.

- No experimental evidence is found of a threshold level of strength below which no damage accumulates.

- There is no significant effect of timber quality on duration of load behaviour for the range of qualities used.

- There is a significant mechanosorptive effect both in terms of increased creep and a shortening of time to failure. It should be noted, however, that results concerning mechanosorption are always dependent on test parameters such as specimen dimensions and magnitude and frequency of climate variations. 
- The parameters of the creep function $(T / \tau)^{b}$ assessed from experimental data are shown to be highly dependent on moisture. Average values of $b$ ranged from 0.23 for dry conditions to 0.35 for varying moisture conditions, while the average doubling time $\tau$ ranged from approximately 2,000 years for dry conditions to 1 month for varying moisture conditions.

- The parameters of the four different duration of load models (Gerhards, Foschi $\&$ Yao, Nielsen and LEFM) are estimated using the Maximum Likelihood Method by which the surviving test specimens can be included in the statistic analysis. The results show that all four damage accumulation models can be calibrated to fit the data very well if the equal rank assumption is used to estimate the short-term strength. By using non-destructive indicators to estimate the short-term strength, reasonable fits are obtained, but with significantly larger model uncertainties than when using the equal rank assumption. This is due to the large scatter of the data points.

- The combined duration of load and moisture effects are evaluated in terms of the stress level $\mathrm{SL}_{50}$ to cause failure after 50 years of permanent load. The $\mathrm{SL}_{50}$ values predicted by the four damage accumulation models and the equal rank assumption agree well with the linear regression and sample median predictions. The predictions obtained using the non-destructive parameters are very scattered as could be expected from the highly uncertain estimates of the model parameters.

- The stress level $\mathrm{SL}_{50}$ was found to be of the order of 0.60 for $\mathrm{MC}=11 \%, 0.50$ for $\mathrm{MC}=20 \%$ and 0.44 for MC varying between 11 and $20 \%$.

- A reliability-based calibration of the duration factors $k_{\bmod }$ is made including the uncertainties related to loads, short and long-term strengths and models for lifetime equal to 50 years. For permanent and imposed library loads, reliability-based estimation of the load-duration factor gives almost the same results as direct, deterministic calibration. This is also the case if statistical uncertainty on the parameters in the damage accumulation models is included.

- 13 years of test data are available. Using Gerhards' model, a sensitivity analysis with surviving tests included shows that it is sufficient to use data from 67 years, i.e. the time span of the tests could be shortened significantly.

Acknowledgments The financial support of the Danish Strategic Research Council within the framework of DSF project 2020-00-0017 is gratefully acknowledged.

\section{References}

CIB W81 (1989) Actions on structures-liveloads in buildings. CIB Publication 116

DS409 (2006) Code of practice for the safety of structures (In Danish). Danish Standards Association DS413 (2003) Code of practice for the structural use of timber (In Danish). Danish Standards Association Eurocode 5 (2004): EN 1995-1-1. Eurocode 5: design of timber structures - part 1-1: general - common rules and rules for buildings

Fewell AR (1986) Testing and analysis carried out as part of the Princes Risborough laboratory's programme to examine the duration of load effect on timber. Western Forintek Spec. Publ. No. SP27 
Foley C (2003) Modeling the effects of knots in structural timber. Doctoral thesis. Division of Structural Engineering. Lund University, Sweden

Foschi RO, Yao ZC (1986) Another look at three duration of load models. Proc. 19th CIB/W18 Meeting, Florence, Italy

Gerhards CC (1979) Time-related effects of loading on wood strength. A linear cumulative damage theory. Wood Sci 11(3):139-144

Gustafsson PJ, Hoffmeyer P, Valentin G (1998) DOL Effect on end-notched beams. Holz Roh- Werkst 56(5):307-317

Hanhijärvi A, Hoffmeyer P, Valentin G (1998) Duration of load behaviour of differently sized timber beams. Holz Roh- Werkst 56(5):285-293

Hoffmeyer P (1990) Failure of wood as influenced by moisture and duration of load. Doctoral dissertation. College of Environmental Science and Forestry, State University of New York, Syracuse, N.Y., USA. http://www.byg.dtu.dk/upload/institutter/byg/trae/dol.pdf

Hoffmeyer P (1993) Non-linear creep caused by slip plane formation. Wood Sci Technol 27(5)

Hoffmeyer P (2003) Strength under long-term loading. In: Thelandersson S, Larsen HJ (eds) Timber engineering. Wiley, New York

Hoffmeyer P, Davidson RW (1989) Mechanosorptive creep mechanism of wood in compression and bending. Wood Sci Technol 23:215-227

JCSS (2006) Joint committee on structural safety-probabilistic model code. http://www.jcss.ethz.ch

Madsen B (1971) Duration of load tests for dry lumber in bending. Structural Research Series, Report No. 3. University of British Columbia, Vancouver, Canada

Nielsen LF (1979) Crack failure of dead-, ramp- and combined loaded viscoelastic materials. Proc. first international conference on wood fracture, Banff, Alberta, Canada

Sørensen JD, Hoffmeyer P (2000) Reliability analysis of structural timber systems. 9th IFIP WG7.5 conference, Ann Arbor

Sørensen JD, Hoffmeyer P (2001) Statistical analysis of data for timber strengths. Paper No. 206. Structural reliability theory, Department of Building Technology and Structural Engineering, Aalborg University

Sørensen JD, Svensson S (2005) Reliability-based modeling of moisture and load duration effects. Proc. COST E24 conf. "probabilistic models in timber engineering", ARBORA edn. Arachon, pp 79-86

Sørensen JD, Svensson S, Stang BD (2005) Reliability-based calibration of load duration factors for timber structures. Struct Saf 27:153-169

Wood LW (1951) Relation of strength of wood to duration of stress. U.S. Forest Products Laboratory. Report No. 1916 